Douglas J. McCauley ${ }^{a} \llbracket$, Paul A. DeSalles ${ }^{a \S}$, Hillary S. Young ${ }^{\mathrm{a}}$, Jonathan P. A. Gardner $^{\mathrm{b}}$, and Fiorenza Micheli ${ }^{\mathrm{c}}$

14 a Department of Ecology, Evolution, and Marine Biology, University of California, Santa

15 Barbara, CA 93106 USA. paul.desalles@lifesci.ucsb.edu and

16 hillary.young@lifesci.ucsb.edu

$17{ }^{\mathrm{b}}$ Centre for Marine Environmental and Economic Research, Victoria University of

18 Wellington, PO Box 600, Wellington 6140 New Zealand. jonathan.gardner@vuw.ac.nz

$19{ }^{\mathrm{c}}$ Hopkins Marine Station, Stanford University, 120 Ocean View Blvd, Pacific Grove, CA

2093950 USA. micheli@stanford.edu

21 Corresponding author. E-mail: douglas.mccauley@lifesci.ucsb.edu; Tel: (805) 893-

22 4972; Fax: (805) 895-5883.

$23 \S_{\text {authors contributed equally }}$

(C) 2016. This manuscript version is made available under the Elsevier user license http://www.elsevier.com/open-access/userlicense/1.0/ 


\section{SHARK BEHAVIOR}

\section{ABSTRACT}

29 Shark species play an important role in shaping marine communities, ecosystems, and

30 community assemblages, yet their high mobility and low abundances in certain locations

31 makes studying the way they interact with these systems difficult. Here high-resolution

32 acoustic cameras are demonstrated as effective tools to study the ecology and behavior of

33 reef and coastal sharks that operate in the vicinity of a near-pristine coral reef atoll. The

34 acoustic camera generated detailed imagery and size measurements from more than 1,000

35 sightings of shark that traversed through a discrete corridor linking two of the atoll's

36 distinct marine habitats, the forereef and offshore pelagic habitat with the atoll's lagoon.

37 Daily shark density and estimated biomass values varied considerably through time, but

38 generally approximated values calculated using less comprehensive and more labor-

39 intensive techniques at this same atoll. Diel patterns in shark movements revealed

40 elevated shark presence during low-light periods of the day (e.g. peak sighting density

41 just after dusk), but weaker links between shark movement patterns and tides. Data

42 gathered through use of this tool extends and reinforces some of the observations made of

43 smaller numbers of sharks using traditional data collection methods while providing

44 unique additional insights into the ways that larger numbers of sharks operate at fine

45 spatial scales over longer periods of time. Behavioral information of this type is critical to

46 developing effective management plans for these vulnerable species. 
47 KEYWORDS: behavior, movement ecology, mobile species, sharks, acoustic camera,

48 sonar

\section{1. INTRODUCTION}

52 Sharks play important roles in maintaining the health, diversity, and resilience of many

53 marine ecosystems. Their presence in marine communities can have multiple direct or

54 indirect effects on trophic interactions, community biomass regulation, and potential

55 whole-ecosystem phase shifts (Bascompte et al., 2005; Ferretti et al., 2010; Heupel et al.,

56 2014). Properly managing shark species and consequently marine ecosystems requires a

57 deeper understanding of how sharks operate within the habitats they frequent and how

58 they transit between habitats (Block et al., 2011; Heupel and Simpfendorfer, 2015; Speed

59 et al., 2010). This enterprise is made doubly important given the fact that many shark

60 species are classified as near-threatened, vulnerable, or endangered (Dulvy et al., 2014).

61 The reduced abundance of certain shark species in a variety of locations coupled

62 with their sometimes transient presence in ecosystems and any potential biases (Ward-

63 Paige et al., 2010) for or against interacting with humans necessitate the exploration and

64 adaptation of new sensing technologies to passively observe shark ecology and behavior

65 in situ, and across a range of spatial scales. The current suite of tools used to study the

66 spatial biology of elasmobranchs (e.g. visual surveys, acoustic telemetry, satellite

67 telemetry, animal-borne cameras, stable isotope analysis) has expanded and continues to

68 produce new insights into the movement patterns of sharks but many of these methods

69 are time, labor, or cost intensive and may sometimes be less well suited to describe fine- 
70 scale patterns of utilization of particular marine habitats (Block et al., 2011; Heithaus et

71 al., 2001; McCauley et al., 2014, 2012b). The details of these small-scale movements and

72 behaviors are vitally important to developing a complete understanding of shark ecology

73 and behavior. For instance, previous studies utilizing stable isotope analyses have

74 indicated high connectivity and frequent movement of reef-associated sharks across

75 different habitat types - reefs, lagoons and pelagic habitat (McCauley et al., 2012b) - but

76 direct observation and quantification of these within-system movements is still scarce.

77 High-resolution acoustic cameras may play an important role in filling this gap in

78 shark research. Acoustic cameras use sonar technology, or pulsed sound wavelengths to

79 produce fast-frame, detailed imaging in even low-light, turbid environments that surpass

80 the range capture and clarity capabilities of traditional optical cameras (Belcher et al.,

81 2002); these cameras also allow for size measurements of detected targets. This

82 technology was recently adapted for ecological applications. Acoustic cameras have been

83 widely used for the study of salmonid behavior but they have been also employed to

84 passively record the behavior and movements of other marine and freshwater organisms

85 (Becker et al., 2011; Burwen et al., 2010; Holmes et al., 2006; Makabe et al., 2012).

86 Some of the previous applications have included surveying the size structure of fish

87 populations (e.g. cape silverside) in estuaries (Becker et al., 2011), describing the

88 behavior of sturgeon in river spawning areas (Crossman et al., 2011), and counting

89 salmon as they migrated upriver (Holmes et al., 2006). Acoustic cameras have also been

90 used in trials to test the willingness of sharks to cross over experimental magnetic barriers

91 to obtain offered baits as means of examining the efficacy of this type of experimental

92 shark deterrent (O’Connell et al., 2014). 
93 Data is presented here that was collected using one class of acoustic camera to

94 study the behavior and space use of a large population of reef sharks that inhabit the

95 waters surrounding Palmyra Atoll - a near-pristine coral ecosystem in the central Pacific

96 Ocean. As a U.S. National Wildlife Refuge with an especially high biomass of apex

97 predators (Sandin et al., 2008). Palmyra confers a unique and valuable opportunity to

98 survey the abundance and size structure of an unexploited reef shark population, and

99 study how sharks transit across reef habitats and how these movements may be related to

100 abiotic variability. This study reports what can be ascertained using the acoustic camera

101 about the density and size structure of sharks in this habitat as well as how shark behavior

102 varied with time of day and tidal period - two abiotic factors that have been shown to

103 affect movement behavior in multiple other shark populations.

104 A major value of using acoustic cameras in marine ecological studies is the

105 potential to gain long-term continuous observations of large numbers of sharks

106 interacting with important parts their environment - insight that may not necessarily be

107 obtained through other methods. This non-invasive tool also obviates the need to capture

108 and tag individuals, captures a greater proportion of the population than may be assessed

109 via fishing methods, and does not influence animal behavior.

110 The behavioral patterns reported here demonstrate the kinds of insight that can be

111 gained from this tool regarding how sharks operate both within and across marine

112 habitats. Proper management of these often highly sensitive species requires access to

113 high quality information about when sharks use a given habitat, what their ecological

114 needs are from that space, and how these dependencies vary temporally and spatially. 


\section{2. MATERIALS AND METHODS}

\section{$117 \quad 2.1$ Study Site}

118 Palmyra Atoll $\left(5^{\circ} 53^{\prime} \mathrm{N}, 162^{\circ} 05^{\prime} \mathrm{W}\right)$ is located in the central Pacific approximately 1,000

119 miles south of Hawai'i. Palmyra is protected as a U.S. National Wildlife Refuge and its

120 lagoon and surrounding coastal waters are managed as "no-take" zones. The historic

121 isolation and modern protection of Palmyra have allowed large reef fishes, particularly

122 sharks, to persist at high abundances that are rarely observed in inhabited and fished reef

123 settings (Sandin et al., 2008; McCauley et al., 2012b). At least 7 species of sharks are

124 common at Palmyra including, blacktip reef sharks (Carcharhinus melanopterus),

125 whitetip reef sharks (Triaenodon obesus), grey reef sharks (Carcharhinus

126 amblyrhynchos), Galapagos sharks (Carcharhinus galapagensis), tiger sharks

127 (Galeocerdo cuvier), scalloped hammerhead sharks (Sphyrna lewini), and lemon sharks

128 (Negaprion brevirostris). Other species are likely to be present, but rare.

129 Palmyra's islets and lagoon morphology underwent significant structural

130 modification during World War II, including extensive expansion of a large natural

131 channel in the Western Lagoon basin (Collen et al., 2009). This channel in its

132 contemporary form measures approximately $1.5 \mathrm{~km}$ long, $80 \mathrm{~m}$ wide, and $8 \mathrm{~m}$ deep. It is

133 characterized by a sandy bottom substratum of relatively uniform depth that is flanked by

134 near-vertical walls of coral rubble. Turbulent flushing through the channel often creates

135 visibility conditions which make video or diver observation difficult or impossible. The

136 channel physically connects Palmyra's forereef and offshore marine habitats to the atoll's

137 lagoon habitats and has been observed to be an important passageway for marine

138 megafauna transiting between these two environments (McCauley et al., 2014). 


\subsection{High-resolution acoustic imaging of shark behavior}

140 The spatially confined nature of Palmyra's main channel presents a tractable arena in

141 which to observe the movement and behavior of sharks transiting between Palmyra's

142 offshore/forereef habitats and lagoon environment. Dual-frequency identification sonar

143 (DIDSON, Sound Metrics Corp., WA, USA) was used to "acoustically gate" a portion of

144 the channel and observe sharks in this corridor (Figure 1). DIDSON is a marine sonar

145 device that permits high-resolution digital imaging of objects within the sonar's field of

146 view (Belcher et al., 2002). The unit was installed mid-way along the channel at $3 \mathrm{~m}$

147 depth on the southern channel side wall. The acoustic camera near-continuously

148 monitored a $41.7 \mathrm{~m}^{3}$ section of channel space (McCauley et al., 2014). The field of view

149 of the acoustic camera is pyramidal in shape with a basal width of $5 \mathrm{~m}$ and height of 2.5

$150 \mathrm{~m}$. The water volume of the sonar field was calculated as $\mathrm{V}=0.041 \mathrm{D}^{3}-0.0052 \mathrm{~m}^{3}$;

151 where $\mathrm{D}$ is the range selected (Han and Uye, 2009). The maximum linear distance

152 visualized by the acoustic camera was $10 \mathrm{~m}$, or approximately $13 \%$ of the width of the

153 channel. As such, the device does not provide a comprehensive view of shark activity in

154 the channel, but rather an unbiased sub-sample of these behavioral patterns. The acoustic

155 camera was positioned to image a section of space directly perpendicular to the channel

156 and was mounted on a vertical channel wall such that few, if any, sharks would transit

157 above or behind the area viewed. The unit was operated during two daily recording

158 sessions (each averaging 9.5 hours) from 2 July 2009 through 29 July 2009 . Recording

159 session length was battery limited and batteries were serviced twice daily at

160 approximately $0700 \mathrm{~h}$ and $1830 \mathrm{~h}$. 
161 Collected data were pre-processed to remove all object-free sections using the

162 DIDSON operating system software. Remaining acoustic footage was manually reviewed

163 and all sharks were enumerated and measured (total length). Field tests of the DIDSON

164 acoustic camera that were conducted using the same range settings as those used in this

165 work report that mean DIDSON measurements of 2,874 fish (sockeye salmon) were on

166 average $1.6 \mathrm{~cm}$ longer than mean lengths obtained from manual measurements (Holmes

167 et al., 2006). Similarly high levels of measurement correspondence were found in other

168 field tests of length using tethered fish and that this correspondence was not range

169 dependent (Burwen et al., 2010). DIDSON derived measurements of shark length in this

170 study were used without correction. The direction of travel of all sharks was categorically

171 recorded (i.e. "entering” lagoon; "exiting” lagoon). Sharks would occasionally change

172 their direction of travel while in the field of view of the acoustic camera. In such

173 instances the sharks' direction was recorded as the final direction by which they exited

174 the field of view. Acoustic camera sensing does not permit identification of unique

175 individuals and consequently individuals that exited and reentered the field of view were

176 necessarily treated in this analysis as new sighting records. Time standardized shark

177 density estimates were generated using the duration of acoustic camera recordings and

178 the water area or volume monitored (for daily shark densities and diel/tidal shark

179 movement patterns, respectively).

180

$181 \quad 2.3$ Shark abundance

182 Daily shark densities (pooled "entering" and "exiting" sharks) were calculated from

183 acoustic camera recordings, and standardized by water area monitored and recorded 
184 minutes. Although the acoustic camera monitors a three-dimensional swath of water,

185 shark density estimates were expressed in two dimensions $\left(\mathrm{m}^{2}\right.$; following (McCauley et

186 al., 2012a)) to facilitate comparison with density values estimated using other survey

187 techniques at Palmyra and elsewhere. Estimates of daily biomass were generated from

188 daily shark counts and lengths of recorded individuals using length-weight conversion

189 values reported in (Froese and Pauly, 2015). Because DIDSON cannot identify individual

190 shark species, two length-weight conversions were used that reflect two general size

191 groupings of sharks (large sharks and all other sharks) species that frequent Palmyra.

192 Lengths of large sharks (i.e., sharks >1.9 m TL; calculated from the largest $C$.

193 amblyrhynchos measured by DJM at Palmyra $(1.75 \mathrm{~m})+10 \%$ to be conservative) were

194 transformed to biomass values using algorithm constants that were averaged for G. cuvier

195 and N. brevirostris. Based on measurements of $>300$ sharks captured at Palmyra

196 (McCauley et al., 2012a, 2012b) and reported species-specific size data (Compagno,

197 1984), these "large shark" observations can with a high degree of certainty be ruled out as

198 grey reef (C. amblyrhynchos), blacktip (C. melanopterus), and whitetip (T. obesus)

199 sharks, the three most common species of sharks recorded on Palmyra's reefs (McCauley

200 et al., 2012a). Lengths of all other sharks were transformed to biomass using algorithm

201 constants that were averaged for C. melanopterus, T. obesus, and C. amblyrhynchos.

202

203 2.4 Diel differences in shark behavior

204 To examine diel variation in shark behavior shark density, directionality of travel, and

205 shark size were compared across a diel partitioning scheme that included two and eight

206 divisions (standardized by water volume monitored and recorded hours). The "two diel" 
207 classification divided each 24 hour period into "day" and "night"; day =0620-1930 h

208 (defined as the beginning to end of local civil twilight), night $=1930-0620 \mathrm{~h}$. The "eight

209 diel" classification divided each 24 hour period into: pre-dawn (0548-0648 h), dawn

210 (0648-0806 h), post-dawn (0806-0906 h), day (0906-1658 h), pre-dusk (1658-1758 h),

211 dusk (1758-1909 h), post-dusk (1909-2009 h), and night (2009-0548 h).

212 This sequential narrowing of diel categories allowed for tiered analysis of daily

213 variation in shark behavior. Boundaries of diel categories were based on measured daily

214 fluctuations in light levels in Palmyra's channel measured directly by light loggers (Onset

215 Computer Corp., MA, USA) placed at 2 and 4 meters depth in the channel adjacent to the 216 acoustic camera.

2182.5 Influence of tide on shark behavior

219 Shark density and directionality of travel were similarly compared across four tidal

220 periods (standardized by water volume monitored and recorded hours): ebb, flow, high

221 slack, and low slack. High slack and low slack were defined as 1 hour periods either side

222 of peak high or low tide events (Cartamil et al., 2003). Local tidal events for Palmyra

223 were determined directly using a pressure sensor (TruBlue 555 KPSI, Esterline Pressure

224 Systems, WA, USA) installed in the West Lagoon.

225

$226 \quad 2.6$ Statistical analyses

227 Comparisons of shark density (across diel/tidal periods), directionality ("entering” versus

228 “exiting" within each diel/tidal period), and size (across diel periods) were made using

229 nonparametric Wilcoxon and Kruskal-Wallis tests, coupled with Holm's sequential 
230 Bonferroni post-hoc corrections in instances where multiple comparisons were computed.

231 All statistics were computed in R (R Development Core Team, 2013).

232

233

234 3. RESULTS

235 A total of 1196 shark observations were made during 443 hours of acoustic camera

236 recording in Palmyra's main channel. Measurements of shark sizes ranged from 0.5 to 3.4

237 meters total length (Figure S1), with a mean size of $1.0 \pm 0.01$ meters. No species-

238 specific diagnostic morphologies (e.g. the hammerhead of S. lewini sharks) were

239 observed during recordings. The maximum number of sharks observed in a single frame

240 was 10 individuals. Individual sharks typically spent $2-10$ seconds within the field of

241 view of the acoustic camera. Ten sharks measured $>1.9 \mathrm{~m} \mathrm{TL}$, ranging from 2.0 to $3.4 \mathrm{~m}$.

242 Daily density of sharks observed during the study period was variable, ranging

243 from 0 to 5.7 sharks $1000 \mathrm{~m}^{-2} \mathrm{~min}^{-1}$ (Figure 2). Daily biomass values ranged from 0 to

$244105 \mathrm{~kg} 1000 \mathrm{~m}^{-2} \mathrm{~min}^{-1}$. These daily shark biomass values largely mirrored variations in

245 daily shark density, except on dates where large sharks were abundant (Figure 2).

246

247 3.1 Diel differences in shark behavior

248 In the two diel classification, the density of sharks moving through the channel at night

249 was more than three times greater than the density of sharks moving through by day ( $W=$

$250252, P=0.02$; Figure 3a). The eight diel classification further revealed that the majority

251 of this difference in diel usage was driven by sharks swimming through the channel

252 during the post-dusk period (i.e. $1909-2009 \mathrm{~h} ; \chi^{2}=37.38, d f=7, P=0.0001$; Figure $3 \mathrm{~b}$ ). 
253 The mean density of sharks $\left(\mathrm{m}^{-3} \mathrm{~h}^{-1}\right)$ recorded at post-dusk was approximately 7 times

254 greater than values observed during the full light diel periods (i.e. post-dawn, day, and

255 pre-dusk).

256 Evaluations of differences in shark directionality within both the two and eight

257 diel classification schemes were only significant for eight diel, with more sharks

258 observed entering the lagoon during post-dawn and post-dusk ( $W=197, P=0.04$ and $W$

$259=407, P=0.0001$, respectively) than exiting the lagoon during the same periods (Figures

$2603 \mathrm{a}$ and 3b). Density of sharks entering the lagoon at post-dusk was greater than shark

261 densities observed during any other time period and more than 4 times greater than the

262 density of sharks exiting the lagoon during the same time period.

263 Comparisons of mean shark sizes in the channel during each of the different diel

264 periods were significantly different for both diel classifications (two diel, $W=78702.05$,

$265 P=0.0001$; eight diel, $\left.\chi^{2}=213.61, d f=7, P=0.0001\right)$, with larger sharks tending to

266 move through the channel at times characterized by lower ambient light (night, post-dusk,

267 pre-dawn). Elucidating specific diel patterns of movement through the channel for the

268 pool of "large sharks", > 1.9 m TL, was statistically difficult given the low sample size $(n$

$269=10$ ), but the majority of these large individuals were observed exiting the lagoon during

270 the day. $80 \%$ of these large shark observations were made at a distance of $\geq 8 \mathrm{~m}$ from the

271 acoustic camera, potentially suggesting behavioral avoidance of the channel ledge.

272

\section{$273 \quad 3.2$ Influence of tide on shark behavior}

274 Measurements of pooled shark density through the channel were significantly different

275 when compared across tidal periods $\left(\chi^{2}=8.57, d f=3, P=0.035\right)$ with highest shark 
276 densities observed during high slack and lowest densities observed during flood tides

277 (Figure 4). Differences in shark density between any two different tidal periods, however,

278 were only weakly pronounced such that post-hoc analysis yielded no significant pair-wise

279 differences. Comparisons of directionality within each tidal period did not yield any

280 significant differences.

281

282

283 4. DISCUSSION

284 This study provides a novel demonstration of how acoustic cameras can be used to

285 describe detailed attributes of the space use and behavior of sharks that provide a

286 valuable complement to data collected using more traditional shark observation methods.

287 The imaging capability of the acoustic camera allowed near-continuous capture of

288 multiple weeks of movement data on shark species that transit across an important habitat

289 boundary at Palmyra Atoll. Insight yielded from acoustic camera observation provides

290 unique bulk insight into the behavioral patterns of populations, rather than just

291 individuals. This tool provides the opportunity for similar kinds of new question asking in

292 research involving other difficult to observe large marine species (e.g. marine mammals,

293 sea turtles) in similar contexts.

294

295 The acoustic camera data collected during this study provide valuable insight into

296 the structure and behavior of the shark population using the main channel at Palmyra.

297 Smaller sized sharks (i.e. < 1.9 m TL) were most commonly observed, matching

298 observation from visual surveys that such species (e.g. blacktip, whitetip, grey reef) are 
299 numerically dominant at Palmyra. Blacktip sharks, C. melanopterus, are the most

300 common shark observed in Palmyra's lagoons and previously reported mean sizes for $C$.

301 melanopterus at Palmyra (Papastamatiou et al., 2009) closely match the mean shark sizes

302 recorded here by the acoustic camera. Additionally, recordings of the ten "large sharks"

303 (i.e. > $1.9 \mathrm{~m} \mathrm{TL}$ ) quantitatively confirms the reports of intermittently sighted large shark

304 species (e.g. G. cuvier or N. brevirostris) in Palmyra's lagoons (Papastamatiou et al.,

305 2014). The mean density of sharks observed using the acoustic camera (1.8 sharks 1000

$306 \mathrm{~m}^{-2} \mathrm{~min}^{-1}$, SE 0.3 sharks $1000 \mathrm{~m}^{-2} \mathrm{~min}^{-1}$ ), while highly variable across days, was similar

307 to average shark density values reported by McCauley et al. (2012a) at Palmyra using

308 traditional video surveys (approximately 1.2 sharks $1000 \mathrm{~m}^{-2} \mathrm{~min}^{-1}$ ). In addition to

309 corroborating data gathered through more time and labor-intensive methods, the acoustic

310 camera highlighted a large temporal variability in the abundance and estimated biomass

311 of sharks transiting through the main channel - continuous temporal information that

312 warrants further investigation into these shark movement patterns and that may not have

313 been collected through traditional video or diver surveys due to physical or time

314 constraints.

315

\section{4.1 Diel differences in shark behavior}

317 The higher density of sharks transiting through the main channel during low-light level

318 hours reflects observations made elsewhere of increased crepuscular activity in several

319 different reef and coastal sharks. Explanations offered for heightened levels of activity

320 for non-filter feeding sharks like this include: individuals capitalizing on opportunities for 
321 higher prey capture rates, thermoregulation, and predator avoidance (Andrews et al.,

322 2009; Garla et al., 2005; McKibben and Nelson, 1986; Sims et al., 2006).

323 Observed peaks in shark densities at the acoustic camera sensing site in Palmyra

324 could represent either a numerical increase in shark abundance (e.g. more sharks arriving

325 during this period to this region to forage) or an increase in the activity of sharks resident

326 in this area (e.g. the same number of sharks looping at higher rates in front of the acoustic

327 camera). Peaks in shark densities specifically recorded during the post-dusk period

328 (1909-2009 h) temporally mirror reported activity peaks (1900-2100 h) in $C$.

329 melanopterus individuals tagged with acoustic transmitters at Palmyra that have been

330 hypothesized to be associated with increases in foraging activity during this period

331 (Papastamatiou et al., 2015). Baited observational trials conducted in the region of the

332 acoustic camera (after the instrument had been removed) revealed that the majority of

333 sharks observed during this period were C. melanopterus suggesting, at least anecdotally,

334 that this species was disproportionally contributing to the abundances of sharks recorded

335 during this specific peak period.

336 The majority of the sharks recorded during the post-dusk peak in activity were

337 observed entering the lagoons. This may represent a stereotyped movement of sharks

338 from the outer reef regions into the lagoons during this period. While sharks such as $C$.

339 melanopterus tracked inside of the lagoons show high site fidelity to particular sections

340 of a lagoon, less is known about the movement of sharks in forereef environments. Stable

341 isotope analysis of reef sharks, particularly blacktips, suggest that sharks captured on the

342 forereef at Palmyra derive some of their energy from lagoonal prey (McCauley et al., 
343 2012b). More work will be required to fully elucidate these forereef/lagoon shark

344 movement patterns.

345 Seven of the ten "large shark" (> $1.9 \mathrm{~m} \mathrm{TL})$ observations recorded using the

346 acoustic camera entered the channel during daylight hours; the limited number of large

347 individuals observed, however, makes it difficult to assess whether these larger sharks

348 exhibit diel patterns in their usage of Palmyra's lagoons.

349

$350 \quad 4.2$ Influence of tide on shark behavior

351 Shark densities across tidal periods were also significantly different overall, however,

352 these tidal differences were much more muted than observed diel differences in density.

353 The highest shark densities occurred during ebb tide and high slack. These results align

354 with Papastamatiou et al. (2015) who also reported C. melanopterus activity at Palmyra

355 was secondarily driven by tidal periods (after time of day), with greatest shark activity

356 occurring during ebb tide. Large scale water movement across Palmyra's sand flats

357 during ebb tides is believed to hydraulically force small fishes off sand flat habitats along

358 discrete corridors, potentially increasing shark foraging success (Papastamatiou et al.,

$3592015,2009)$. Likewise, transits into previously inaccessible habitats for food resources

360 during high slack has been observed in other shark populations (Ackerman et al., 2000;

361 Campos et al., 2009; Carlisle and Starr, 2009) and could potentially explain high shark

362 densities during this high water tidal period.

363

364

365 


\section{$366 \quad 4.3$ Application to conservation and management}

367 Data derived from acoustic cameras can play an important role in designing more

368 strategic interventions to conserve and manage shark populations. In regions where

369 complete large-scale fishing closures (e.g. island level) are not tenable, management can

370 be made more intelligent and effective by demarcating specific habitats that are more

371 readily used for protection or by preventing harvest during times when species activity in

372 a habitat is particularly elevated. Such information could be relevant, for example, to

373 regions like the Great Barrier Reef that have adaptive multi-tiered zoning plans (McCook

374 et al., 2010) and to the placement of temporal closures that have been considered as tools

375 for protecting coral reef predators (Beets and Friedlander, 1999). Results from this work

376 at Palmyra, for example, suggest that shark populations would likely profit by preventing

377 artisanal reef gillnetting during post-dusk hours in reef channels when shark transit rates

378 peak. Lastly, this data can help in important ways to identify the location and use of

379 marine corridors by sensitive marine species. While the conservation significance and

380 ecological use of corridors by large consumers has been well studied on land (Hilty et al.,

381 2012) - data deficiency abounds in ocean ecosystems, despite recognition that corridors

382 may be important in reef and coastal settings (Mumby et al., 2004; Pendoley et al., 2014).

385 5. Conclusions

386 This work helps to demonstrate how high-resolution acoustic cameras can be employed

387 to describe important attributes of shark behavioral ecology in field settings. This tool is

388 not, however, without its weaknesses. Its principle shortcoming is that it cannot identify 
389 individuals. This complicates attempts to estimate true densities of sharks, introduces the

390 problem of over-counting survey targets, and makes it more challenging to differentiate

391 between peaks in shark density and peaks in activity level. Some of these deficiencies

392 problematize other survey methods (e.g. video observation) - although unique markings

393 that can help differentiate individuals can be more apparent in these other methods.

394 The utility of the acoustic camera in this study was maximized by the physical

395 setting in which sensing took place; i.e. an ecologically important corridor and a discrete

396 habitat type where visibility makes observation using alternative means challenging.

397 Future studies can likewise capitalize on the value of this tool by using it in environments

398 where fishes are physically constrained through natural or artificial environmental

399 gateways (e.g. mouths or channels in harbors, estuaries, bays or mangroves) or where

400 activity takes place on relatively discrete marine habitats (e.g. patch reefs, wrecks,

401 boulder fields, or seamounts). In such situations the tool should most often be conceived

402 of as a method for sub-sampling behavioral patterns, as the sensing area of the acoustic

403 camera may not cover the entire are of the environmental feature. All such contexts

404 represent environments where additional data on shark behavior would be of value.

405 Alternatively, acoustic camera units could be operated in series to cover more area and

406 extend the reach of question asking possibilities for mobile targets like sharks.

407 This case study provides a useful view of how acoustic cameras can efficiently

408 confirm and extend the observations of shark ecology and behavior made using alternate

409 methods. At Palmyra, the >1,000 shark sighting records generated using the acoustic

410 camera help us to confirm that the tens of animals tagged in this system are exhibiting

411 behaviors similar to those exhibited by the broader shark population and were able to 
412 better explore the statistical relationships between behavior and core environmental

413 parameters with increased statistical rigor. New behaviors were also observed. The

414 acoustic camera collected first observations of larger sharks that are too rare to study

415 rigorously using traditional tagging and underwater observation methods. The data also

416 revealed what appears to be a stereotyped transit of forereef sharks into lagoons that has

417 not yet been directly observed in this site using other methods. Such observation may be

418 of even greater value in contexts where sharks are more rare and use of alternative data

419 collection methods is untenable. Acoustic cameras have a great deal of potential for

420 future applications in the study of sharks in a range of contexts. Data collected using this

421 tool will usefully increase the confidence and completeness of the understanding of shark

422 behavioral ecology and provide a valuable source of new information on habitat

423 connectivity and shark movement that can be utilized to improve shark management

424 practices.

425

426

427 ACKNOWLEDGEMENTS

428 Thanks to The Nature Conservancy and U.S. Fish and Wildlife Service for field support

429 and research permission. Funding was provided by the National Science Foundation,

430 Stanford University, the Woods Institute for the Environment, and Victoria University of

431 Wellington. Thanks also to Sound Metrics Corp. for providing invaluable technical

432 assistance. For important contributions in the laboratory and field, thanks to: A. Briggs,

433 C. Burniske, M. DeGraff, E. Hoffman, T. Jen, A. Miller-ter Kuile, A. McInturff, N. 
434 Wenner, and E. Wulczyn. This is contribution number 0123 from the Palmyra Atoll

435 Research Consortium (PARC).

436

437

438 REFERENCES

439 Ackerman, J.T., Kondratieff, M.C., Matern, S.A., Cech, J.J., 2000. Tidal influence on

440 spatial dynamics of leopard sharks, Triakis semifasciata, in Tomales Bay,

441 California. Environmental Biology of Fishes 58, 33-43.

442 doi:10.1023/A:1007657019696

443 Andrews, K.S., Williams, G.D., Farrer, D., Tolimieri, N., Harvey, C.J., Bargmann, G.,

444 Levin, P.S., 2009. Diel activity patterns of sixgill sharks, Hexanchus griseus: the

445 ups and downs of an apex predator. Animal Behaviour 78, 525-536.

446 doi:10.1016/j.anbehav.2009.05.027

447 Bascompte, J., Melián, C.J., Sala, E., 2005. Interaction strength combinations and the

$448 \quad$ overfishing of a marine food web. PNAS 102, 5443-5447.

449 doi:10.1073/pnas.0501562102

450 Becker, A., Whitfield, A.K., Cowley, P.D., Järnegren, J., Naesje, T.F., 2011. An

451 assessment of the size structure, distribution and behaviour of fish populations

452 within a temporarily closed estuary using dual frequency identification sonar

453 (DIDSON). J. Fish Biol. 79, 761-775. doi:10.1111/j.1095-8649.2011.03057.x

454 Beets, J., Friedlander, A., 1999. Evaluation of a conservation strategy: a spawning

455 aggregation closure for red hind, Epinephelus guttatus, in the U.S. Virgin Islands.

456 Environmental Biology of Fishes 55, 91-98. doi:10.1023/A:1007404421518 
457 Belcher, E., Hanot, W., Burch, J., 2002. Dual-Frequency Identification Sonar (DIDSON), 458 in: Proceedings of the 2002 International Symposium on Underwater Technology, 459 2002. Presented at the Proceedings of the 2002 International Symposium on $460 \quad$ Underwater Technology, 2002, pp. 187-192. doi:10.1109/UT.2002.1002424

461 Block, B.A., Jonsen, I.D., Jorgensen, S.J., Winship, A.J., Shaffer, S.A., Bograd, S.J., 462 Hazen, E.L., Foley, D.G., Breed, G.A., Harrison, A.-L., Ganong, J.E.,

463 Swithenbank, A., Castleton, M., Dewar, H., Mate, B.R., Shillinger, G.L.,

464 Schaefer, K.M., Benson, S.R., Weise, M.J., Henry, R.W., Costa, D.P., 2011.

465 Tracking apex marine predator movements in a dynamic ocean. Nature $475,86-$ 46690. doi:10.1038/nature10082

467 Burwen, D.L., Fleischman, S.J., Miller, J.D., 2010. Accuracy and precision of salmon 468 length estimates taken from DIDSON sonar images. Transactions of the American $469 \quad$ Fisheries Society 139, 1306-1314. doi:10.1577/T09-173.1

470 Campos, B.R., Fish, M.A., Jones, G., Riley, R.W., Allen, P.J., Klimley, P.A., Jr, J.J.C., 471 Kelly, J.T., 2009. Movements of brown smoothhounds, Mustelus henlei, in 472 Tomales Bay, California. Environ Biol Fish 85, 3-13. doi:10.1007/s10641-009$473 \quad 9462-\mathrm{y}$

474 Carlisle, A.B., Starr, R.M., 2009. Habitat use, residency, and seasonal distribution of 475 female leopard sharks Triakis semifasciata in Elkhorn Slough, California. Mar 476 Ecol Prog Ser 380, 213-228. doi:10.3354/meps07907

477 Cartamil, D.P., Vaudo, J.J., Lowe, C.G., Wetherbee, B.M., Holland, K.N., 2003. Diel 478 movement patterns of the Hawaiian stingray, Dasyatis lata: implications for 
479

480

481

482

483

484

485

486

487

488

489

490

491

492

493

494

495

496

497

498

499

500

ecological interactions between sympatric elasmobranch species. Marine Biology 142, 841-847. doi:10.1007/s00227-003-1014-y

Collen, J.D., Garton, D.W., Gardner, J.P.A., 2009. Shoreline changes and sediment redistribution at Palmyra Atoll (Equatorial Pacific Ocean): 1874-Present. Journal of Coastal Research 711-722. doi:10.2112/08-1007.1

Compagno, L.J.V., 1984. Sharks of the world: an annot. and ill. catalogue of shark species known to date. United Nations Development Programme, Food and Agriculture Organization of the United Nations, Rome.

Crossman, J.A., Martel, G., Johnson, P.N., Bray, K., 2011. The use of Dual-frequency IDentification SONar (DIDSON) to document white sturgeon activity in the Columbia River, Canada. Journal of Applied Ichthyology 27, 53-57. doi:10.1111/j.1439-0426.2011.01832.x

Dulvy, N.K., Fowler, S.L., Musick, J.A., Cavanagh, R.D., Kyne, P.M., Harrison, L.R., Carlson, J.K., Davidson, L.N., Fordham, S.V., Francis, M.P., Pollock, C.M., Simpfendorfer, C.A., Burgess, G.H., Carpenter, K.E., Compagno, L.J., Ebert, D.A., Gibson, C., Heupel, M.R., Livingstone, S.R., Sanciangco, J.C., Stevens, J.D., Valenti, S., White, W.T., 2014. Extinction risk and conservation of the world's sharks and rays. eLife Sciences 3, e00590. doi:10.7554/eLife.00590

Ferretti, F., Worm, B., Britten, G.L., Heithaus, M.R., Lotze, H.K., 2010. Patterns and ecosystem consequences of shark declines in the ocean. Ecology Letters 13, 1055-1071. doi:10.1111/j.1461-0248.2010.01489.x 
501 Garla, R.C., Chapman, D.D., Wetherbee, B.M., Shivji, M., 2005. Movement patterns of

502 young Caribbean reef sharks, Carcharhinus perezi, at Fernando de Noronha

503 Archipelago, Brazil: the potential of marine protected areas for conservation of a

504 nursery ground. Marine Biology 149, 189-199. doi:10.1007/s00227-005-0201-4

505 Han, C.-H., Uye, S.-I., 2009. Quantification of the abundance and distribution of the

506 common jellyfish Aurelia aurita s.l. with a Dual-frequency IDentification SONar

507 (DIDSON). J. Plankton Res. fbp029. doi:10.1093/plankt/fbp029

508 Heithaus, M.R., Marshall, G.J., Buhleier, B.M., Dill, L.M., 2001. Employing Crittercam

509 to study habitat use and behavior of large sharks. Mar Ecol Prog Ser 209, 307-

310 310. doi:10.3354/meps209307

511 Heupel, M.R., Knip, D.M., Simpfendorfer, C.A., Dulvy, N.K., 2014. REVIEW Sizing up

512 the ecological role of sharks as predators. Mar Ecol Prog Ser 495, 291-298.

513 doi:10.3354/meps 10597

514 Heupel, M.R., Simpfendorfer, C.A., 2015. Long-term movement patterns of a coral reef

515 predator. Coral Reefs 34, 679-691. doi:10.1007/s00338-015-1272-4

516 Hilty, J.A., Jr, W.Z.L., Merenlender, A., 2012. Corridor Ecology: The Science and

517 Practice of Linking Landscapes for Biodiversity Conservation. Island Press.

518 Holmes, J.A., Cronkite, G.M.W., Enzenhofer, H.J., Mulligan, T.J., 2006. Accuracy and

519 precision of fish-count data from a "dual-frequency identification sonar"

520 (DIDSON) imaging system. ICES J. Mar. Sci. 63, 543-555.

$521 \quad$ doi:10.1016/j.icesjms.2005.08.015

522 Makabe, R., Kurihara, T., Uye, S.-I., 2012. Spatio-temporal distribution and seasonal

523 population dynamics of the jellyfish Aurelia aurita s.l. studied with Dual- 
524 frequency IDentification SONar (DIDSON). J. Plankton Res. 34, 936-950.

525 doi:10.1093/plankt/fbs057

526 McCauley, D.J., DeSalles, P.A., Young, H.S., Papastamatiou, Y.P., Caselle, J.E., Deakos,

527 M.H., Gardner, J.P.A., Garton, D.W., Collen, J.D., Micheli, F., 2014. Reliance of

528 mobile species on sensitive habitats: a case study of manta rays (Manta alfredi)

529 and lagoons. Mar Biol 161, 1987-1998. doi:10.1007/s00227-014-2478-7

530 McCauley, D.J., McLean, K.A., Bauer, J., Young, H.S., Micheli, F., 2012a. Evaluating

531 the performance of methods for estimating the abundance of rapidly declining

532 coastal shark populations. Ecological Applications 22, 385-392. doi:10.1890/11-

$533 \quad 1059.1$

534 McCauley, D.J., Young, H.S., Dunbar, R.B., Estes, J.A., Semmens, B.X., Micheli, F.,

$5352012 b$. Assessing the effects of large mobile predators on ecosystem connectivity.

536 Ecological Applications 22, 1711-1717. doi:10.1890/11-1653.1

537 McCook, L.J., Ayling, T., Cappo, M., Choat, J.H., Evans, R.D., Freitas, D.M.D., Heupel,

538 M., Hughes, T.P., Jones, G.P., Mapstone, B., Marsh, H., Mills, M., Molloy, F.J.,

539 Pitcher, C.R., Pressey, R.L., Russ, G.R., Sutton, S., Sweatman, H., Tobin, R.,

540 Wachenfeld, D.R., Williamson, D.H., 2010. Adaptive management of the Great

541 Barrier Reef: A globally significant demonstration of the benefits of networks of

542 marine reserves. PNAS 107, 18278-18285. doi:10.1073/pnas.0909335107

543 McKibben, J.N., Nelson, D.R., 1986. Patterns of movement and grouping of gray reef

544 sharks, Carcharhinus amblyrhynchos, at Enewetak, Marshall Islands. Bulletin of

$545 \quad$ Marine Science 38, 89-110. 
546 Mumby, P.J., Edwards, A.J., Ernesto Arias-González, J., Lindeman, K.C., Blackwell, 547 P.G., Gall, A., Gorczynska, M.I., Harborne, A.R., Pescod, C.L., Renken, H., C. C.

548 Wabnitz, C., Llewellyn, G., 2004. Mangroves enhance the biomass of coral reef

549 fish communities in the Caribbean. Nature 427, 533-536.

550 doi:10.1038/nature02286

551 O’Connell, C.P., Hyun, S.-Y., Rillahan, C.B., He, P., 2014. Bull shark (Carcharhinus

552 leucas) exclusion properties of the sharksafe barrier and behavioral validation

553 using the ARIS technology. Global Ecology and Conservation 2, 300-314.

$554 \quad$ doi:10.1016/j.gecco.2014.10.008

555 Papastamatiou, Y.P., Caselle, J.E., Friedlander, A.M., Lowe, C.G., 2009. Distribution,

556 size frequency, and sex ratios of blacktip reef sharks Carcharhinus melanopterus

557 at Palmyra Atoll: a predator-dominated ecosystem. Journal of Fish Biology 75, $558 \quad$ 647-654. doi:10.1111/j.1095-8649.2009.02329.x

559 Papastamatiou, Y.P., Watanabe, Y.Y., Bradley, D., Dee, L.E., Weng, K., Lowe, C.G., 560 Caselle, J.E., 2015. Drivers of Daily Routines in an Ectothermic Marine Predator: $561 \quad$ Hunt Warm, Rest Warmer? PLoS ONE 10, e0127807.

562 doi:10.1371/journal.pone.0127807

563 Papastamatiou, Y.P., Wood, C.L., Bradley, D., McCauley, D.J., Pollock, A.L., Caselle, 564 J.E., 2014. First records of the sicklefin lemon shark, Negaprion acutidens, at 565 Palmyra Atoll, central Pacific: a recent colonization event? Marine Biodiversity $566 \quad$ Records 7, e114 (3 pages). doi:10.1017/S175526721400116X 
567 Pendoley, K.L., Schofield, G., Whittock, P.A., Ierodiaconou, D., Hays, G.C., 2014.

568 Protected species use of a coastal marine migratory corridor connecting marine

569 protected areas. Mar Biol 161, 1455-1466. doi:10.1007/s00227-014-2433-7

570 R Development Core Team, 2013. R: a language and environment for statistical

$571 \quad$ computing. R Foundation for Statistical Computing.

572 Sandin, S.A., Smith, J.E., DeMartini, E.E., Dinsdale, E.A., Donner, S.D., Friedlander, 573 A.M., Konotchick, T., Malay, M., Maragos, J.E., Obura, D., Pantos, O., Paulay, $574 \quad$ G., Richie, M., Rohwer, F., Schroeder, R.E., Walsh, S., Jackson, J.B.C., 575 Knowlton, N., Sala, E., 2008. Baselines and degradation of coral reefs in the $576 \quad$ Northern Line Islands. PLoS ONE 3, e1548. doi:10.1371/journal.pone.0001548 577 Sims, D.W., Wearmouth, V.J., Southall, E.J., Hill, J.M., Moore, P., Rawlinson, K., 578 Hutchinson, N., Budd, G.C., Righton, D., Metcalfe, J.D., Nash, J.P., Morritt, D., 5792006 . Hunt warm, rest cool: bioenergetic strategy underlying diel vertical $580 \quad$ migration of a benthic shark. J Anim Ecol 75, 176-190.

581 Speed, C.W., Field, I.C., Meekan, M.G., Bradshaw, C.J.A., 2010. REVIEW Complexities 582 of coastal shark movements and their implications for management. Mar Ecol $583 \quad$ Prog Ser 408, 275-293. doi:10.3354/meps08581

584 Ward-Paige, C., Mills Flemming, J., Lotze, H.K., 2010. Overestimating fish counts by 585 non-instantaneous visual censuses: consequences for population and community 586 descriptions. PLoS ONE 5, e11722. doi:10.1371/journal.pone.0011722 


\section{FIGURES}

Figure 1.

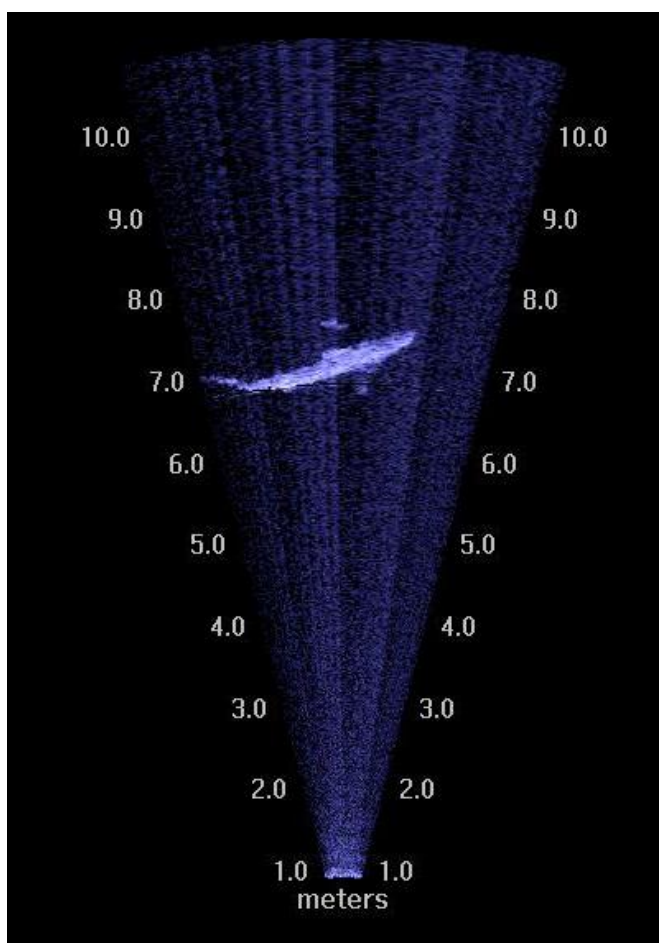

Figure 2.

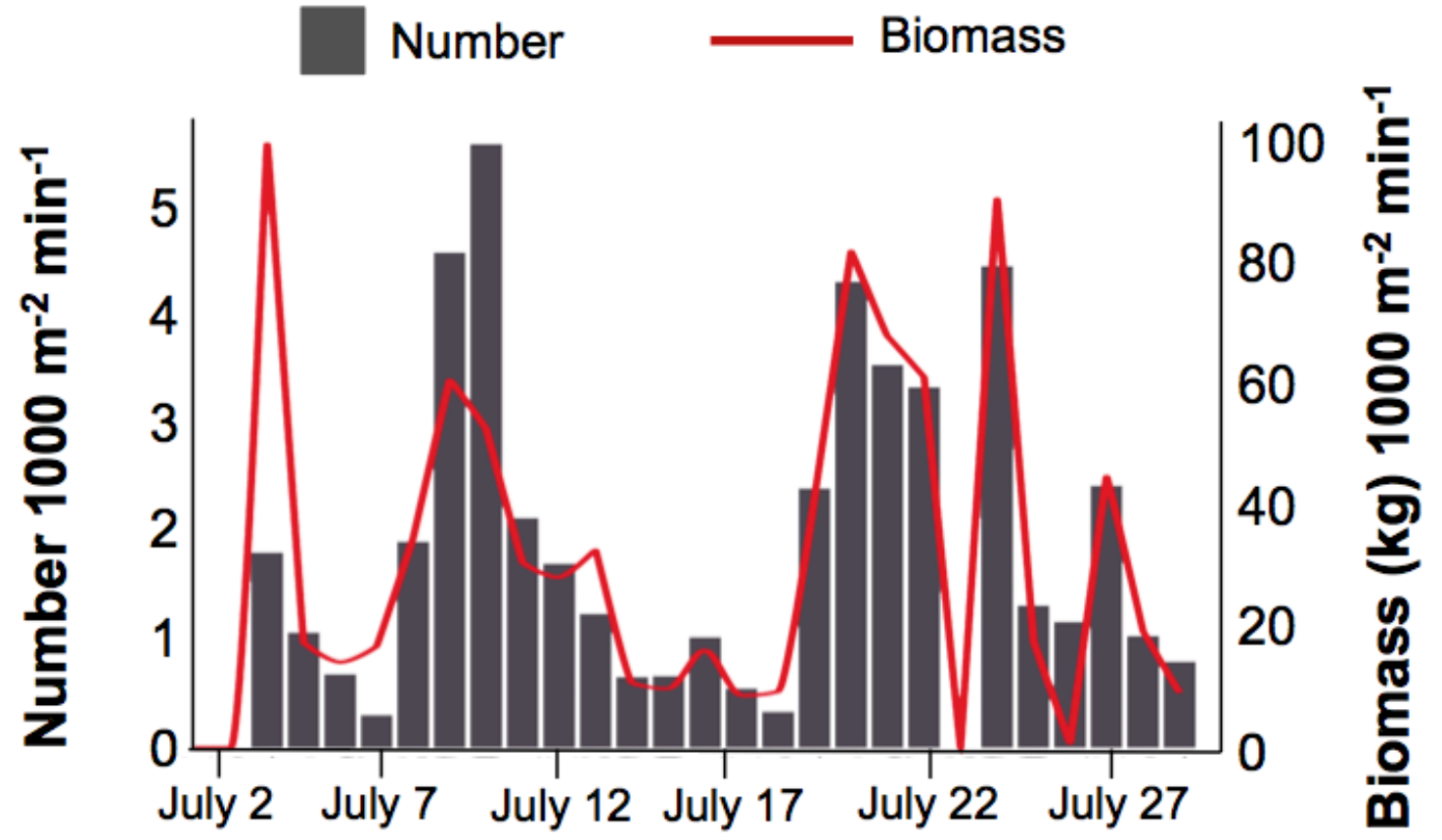


Figure 3.
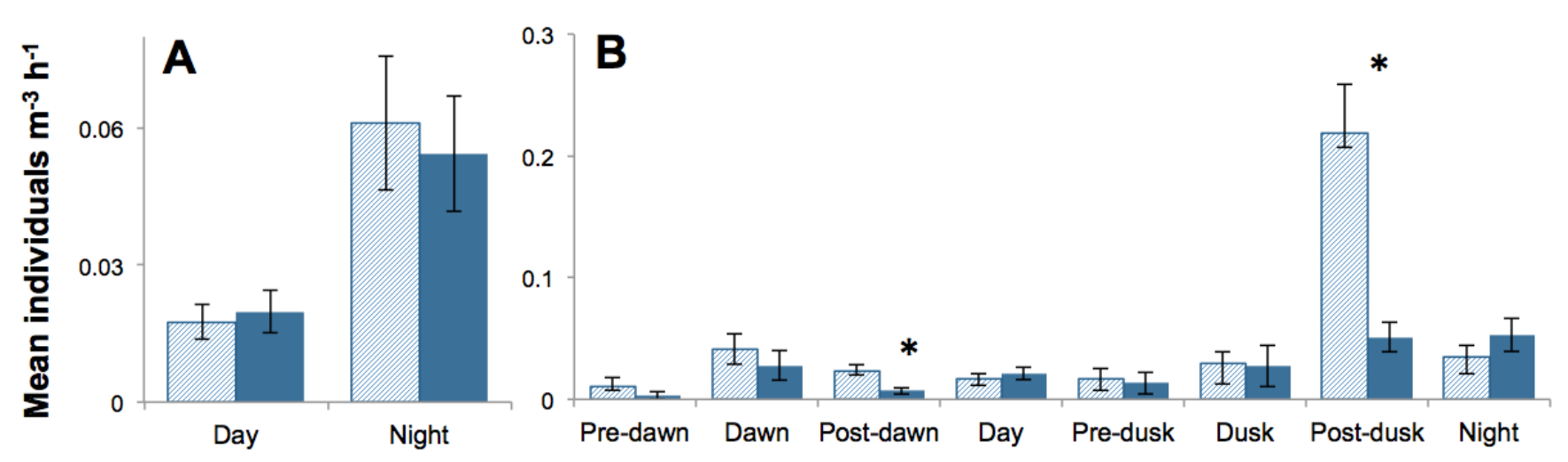

Figure 4.

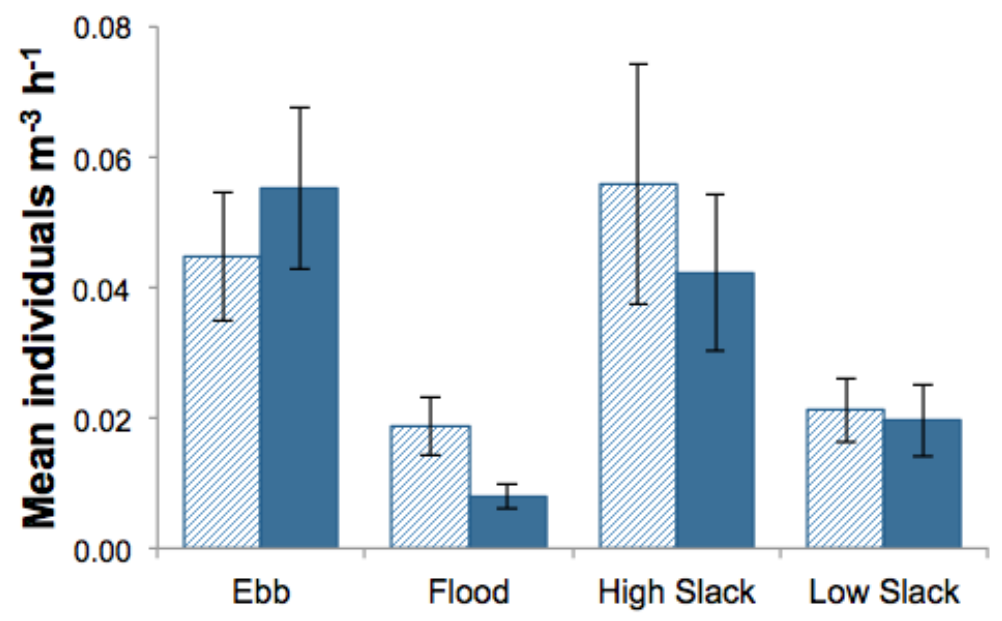




\section{FIGURE LEGENDS (COLOR)}

Figure 1. Acoustic camera recorded image of a shark $(2.8 \mathrm{~m} \mathrm{TL})$ moving through the sonar unit's field of view. Numbers alongside the field-of-view represent object distance from camera.

Figure 2. Daily shark density (grey bars) and estimated biomass (red line) recorded by acoustic camera during the study period.

Figure 3. Density of sharks (mean $\pm \mathrm{SE}$ ) recorded across diel periods with directionality (entering, cross-hatched bars; exiting, solid bars). A. Two diel classification. Diel periods were not significantly different (after post hoc correction; entrances and exits pooled). There were no statistical differences between entrance and exit rates within each period. B. Eight diel classification. Pre-dawn, post-dawn, day, pre-dusk, and dusk were significantly different from post-dusk, and pre-dusk was significantly different from night (after post hoc correction; entrances and exits pooled). Diel periods marked with an asterisk denote statistical difference between entrance and exit rates within that period.

Figure 4. Density of sharks (mean \pm SE) recorded across four tidal periods with directionality (entering, cross-hatched bars; exiting, solid bars). No pair of tidal periods were significantly different from each other (after post hoc correction; entrances and exits pooled). There were no statistical differences between entrance and exit rates within each period. 